\title{
Knowledge and Management of Pediatricians About Children's Oral Health
}

\author{
Pinar Demir Derve Bilmez Selen \\ Department of Pediatric Dentistry, Faculty of Dentistry, Inonu University, Malatya, Turkey.
}

Correspondence Author: Merve Bilmez Selen

E-mail: mervebilmez89@gmail.com

Received: $23.02 .2021 \quad$ Accepted: 05.08 .2021

\begin{abstract}
Objective: This study aims to analyze the knowledge level of pediatricians in Turkey regarding dentistry, oral-dental health, some common oral diseases and to evaluate their approach to their patients from a dental point of view.

Methods: A total of 260 pediatricians responded to a 26-question electronic survey about their personal information and knowledge about children's oral health. The data obtained were analyzed using the $t$ test, Anova and chi-square tests.

Results: The survey was answered by 260 pediatricians. The mean pediatricians' knowledge score was $9.55 \pm 2.85$ ( $m i n-m a x: 3$ to 22 ) and the median score was nine. The number of physicians who didn't know that cariogenic microorganisms can be transmitted from mother to baby was 161 (62\%). It was determined that the pediatricians chose the option "No idea" about protective and preventive applications such as fissure sealants (66.1\%), topical fluoride applications (53.4\%), space maintainer/child prosthesis (67.3\%) and hence they don't have sufficient information.
\end{abstract}

Conclusion: Lack of information and training seems to limit the role of pediatricians in children's oral and dental health. It should be ensured that there are stronger cooperation and communication between pediatric dentists and pediatricians.

Keywords: Preventive Dentistry, Oral Health, Pediatricians, Dental Care for Children, Pediatric Dentistry.

\section{INTRODUCTION}

Oral health is an integral part of children's overall health. Dental caries is considered the most common childhood disease with significant consequences. It has been reported to be five times more than asthma and seven times more than high fever (1).

Dental caries is an infectious disease caused by cariogenic bacteria, diet, and host sensitivity (2). These types of oral diseases can be prevented and controlled through training provided for parents. In the United States of America (USA), dental caries is observed on the primary teeth of approximately $31 \%$ to $53 \%$ of children between the ages of 2 and 8 (3), and it affects $75 \%$ of children by the age of 15 (4). The studies conducted in Turkey have reported even higher rates of dental caries. In studies performed on preschool children, the presence of dental caries was reported in $74.1 \%$ of children between the ages of 3 to 6 and $84.9 \%$ of children between the ages of 5 to 9 years $(5,6)$.

Especially in developing countries, it is reported that the incidence of dental caries has increased 5-10 times due to socioeconomic reasons, diet and insufficient or inappropriate oral hygiene (7). In developed western countries such as Finland, Norway, and Germany, the prevalence of caries in children and young individuals was shown to have decreased rapidly in the 1970s and 1980s (8). This decrease was attributed to various factors such as the use of fluoridecontaining toothpaste, changes in sugar consumption, increased socioeconomic level, dentistry services becoming widespread, application of basic protective and preventive treatments, increased awareness of personal oral hygiene practice (8).

As healthcare professionals responsible for the overall health of children, pediatricians often face dental cariesrelated morbidity. Since pediatricians are the first healthcare professionals to see children, they also have a unique position in identifying and directing diseases related to oral and dental health (9). Evidence in the literature indicates that parents systematically consult pediatricians, regarding dental queries during the first year of their children's life, when the frequency of visits to the pediatrician and pediatric dentist 
is examined, regardless of the nature of the service sought (public or private) (10). The development of dental caries can be prevented if pediatricians detect dental caries and raise awareness of families about preventive measures (11).

This study aims to analyze the knowledge level of pediatricians in Turkey regarding dentistry, oral and dental health, and some common oral and dental diseases, and to evaluate their approach to their patients from a dental point of view.

\section{METHODS}

The study was approved by the Non-Interventional Clinical Research Ethics Committee of Inonu University (Protocol: 2020/573). This study is random demographic research that evaluated pediatricians' oral and dental health knowledge, their attitudes towards oral health and nutrition during infant controls and their approach to certain oral pathologies. The study was explained to the children's parents, whose intraoral photographs were used in the questionnaire and the article, and the informed consent form was signed.

The questionnaire was kept short so that the length of the survey was not negatively reflected in the answers of the respondents, and it was prepared as 26 questions on Google forms. While creating questions, five pediatricians, one public health specialist, and five pediatric dentists were consulted, and the recommendations of the physicians were reflected in the questionnaire items.

The study population was accessed by using case sharing platforms that pediatricians frequently use. A message which contained a participation link and a short text describing the study was sent to pediatricians who were members of these platforms.

The questions are given in Tables 1, 2, 3, 4 together with the findings. The correct answers are marked with an ** sign.

The sample of this study was determined by power analysis. According to the calculations made using the $\mathrm{G} *$ power 3.1 program; The sample size was determined as minimum 252 with 0.25 effect size, 0.05 margin of error, 0.95 confidence level, and 0.95 universe representation power (12).

The analysis of the data included in the study was made with the SPSS (Statistical Program in Social Sciences) 25 program. In the study, quantitative data were presented in "Mean \pm Standard deviation", and qualitative data were presented in numbers and percentages. Whether the data included in the study conformed to the normal distribution was checked with the Kolmogorov Smirnov Test. The significance level ( $p$ ) was taken as 0.05 for the comparison tests. Since the data showed normal distribution, the significance test (t test) and the ANOVA test were used for the difference between the two averages. The Duncan multiple comparison (post-hoc) test was used to determine the groups with differences in the ANOVA test, as variance homogeneity was provided. In addition, qualitative data calculated by chi-square test.

\section{RESULTS}

The survey was sent to 1830 pediatricians across the country through message, 260 of them answered the survey, and the participation rate was calculated as $14.2 \%$. Survey questions and answers are given in Tables 1, 2, 3, 4.

The pediatricians' mean knowledge score about oral health was $9.55 \pm 2.85$ and the median score was nine (min-max: 3 to 22). A statistically significant difference was found between male and female according to the total scores of the participants included in the study ( $p<0.05$, Table 5$)$. A statistically significant difference was found between the age and working year groups according to the total scores of the participants included in the study ( $p<0.05$, Table 5). Duncan Multiple Comparisons test was conducted to see which groups differed for both variables, since variance homogeneity condition was provided. For working years; A statistically significant difference was found between 0-5 years, 5-10 years and 15 years and above in terms of scores ( $p<0.05)$, but there was no difference between the other groups ( $p<0.05$, Table 5 ).

Table 1. Pediatrician's demographic informations Gender Value*

\begin{tabular}{|l|l|}
\hline Female & $56 \%(n=146)$ \\
\hline Male & $44 \%(n=114)$ \\
\hline Average of age & $35.7 \pm 6,3$ \\
\hline Years of professional experience & $49.6 \%(n=129)$ \\
\hline $0-5$ & $23.8 \%(n=62)$ \\
\hline $5-10$ & $16.2 \%(n=42)$ \\
\hline $10-15$ & $10.4 \%(n=27)$ \\
\hline 15 and over &
\end{tabular}

*Values are evaluated as percent (\%). $n=$ number of people.

Pediatricians correctly answered the eruption time of the first permanent molar with $42.3 \%$, by choosing six years of age. The oral cavity of an eight-year-old girl was photographed upon taking the consent of the parents, and the photo was attached to the questionnaire (Figure 1). The participants were asked to identify the first permanent molar among the numbered teeth in Figure 1. 35\% of the physicians answered this question correctly (Figure 1). There was no significant difference in the rate of correct answers to these two questions by gender $(p=0.561$, $\mathrm{p}=0,693$, Table 6).

When pediatricians were asked how often they encountered patients with an ectopic eruption of permanent lower incisors as in Figure 2; 4\% stated that they met it once a week, $14 \%$ said once a month, $40 \%$ once a year and $42 \%$ answered that they had never met any. $76.5 \%$ of the physicians thought that this situation may cause crowding 
and $85.3 \%$ of them thought that orthodontic treatment might be necessary.

While $48.8 \%$ of the physicians who participated in the survey correctly diagnosed primary herpetic gingivostomatitis (PHG) in the photograph, in the next question, $64.5 \%$ found it appropriate to prescribe oral antibiotics for treating this disease. A significant relationship was found between medical experience and the ability to treat PHG $(p=0.270)$. $46.4 \%$ of physicians with 15 or more experience treated PHG correctly (Table 7).

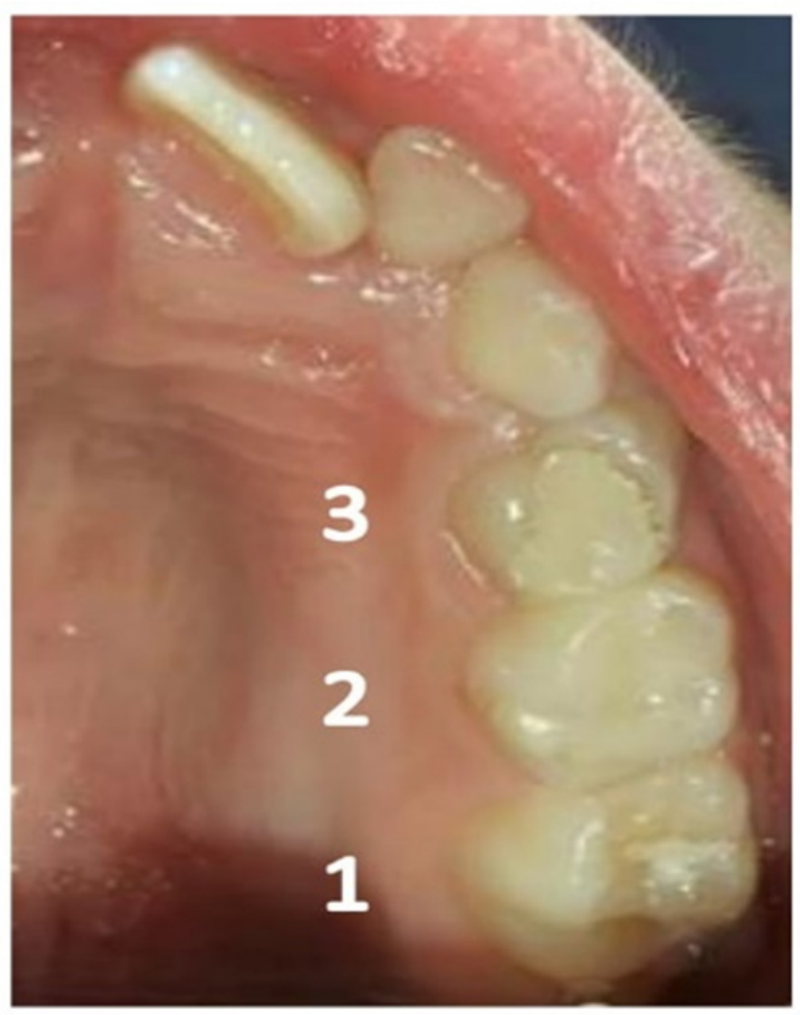

Figure 1. The intraoral photograph of an eight-year-old girl. The participants were asked to identify the first permanent molar among the numbered teeth.

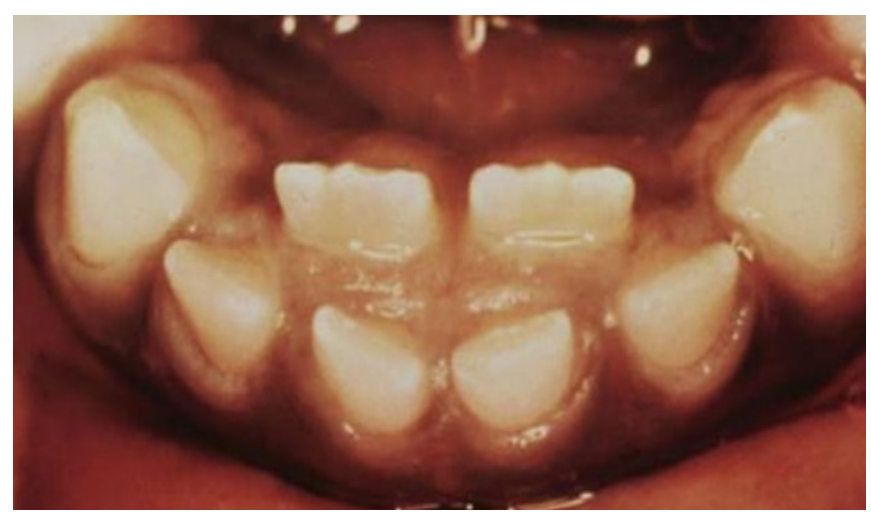

Figure 2. The intraoral photograph of a six-year-old girl with an ectopic eruption of permanent lower incisors. Praticipants were asked "How often they encountered patients with an ectopic eruption and may this situation may cause crowding and orthodontic treatment be necessary?".
When asked about the treatment approach to the patient with lodge abscess caused by teeth, the rate of those who responded that the patient should be treated with combined antibiotic IM/IV (aerob + anaerobe) in hospital conditions was $77 \%$. $20 \%$ preferred to prescribe a combined oral antibiotic and refer the patient to the dentist.

Table 2. Questions and answers about oral examination of 0-1 years old children

\begin{tabular}{|c|c|c|}
\hline & \multicolumn{2}{|l|}{ Value* } \\
\hline \multicolumn{3}{|c|}{ When do you recommend the first dental examination? } \\
\hline With the first tooth eruption $* *$ & \multicolumn{2}{|l|}{$27 \%(n=70)$} \\
\hline After the age of 1 & \multicolumn{2}{|l|}{$26.6 \%(n=69)$} \\
\hline After the age of 2 & \multicolumn{2}{|l|}{$27.3 \%(n=71)$} \\
\hline I don't recommend in routine/ I forget & \multicolumn{2}{|l|}{$19.3 \%(n=50)$} \\
\hline \multicolumn{3}{|c|}{ How often do you recommend routine dentist control to your patients? } \\
\hline Every 6 months $* *$ & \multicolumn{2}{|l|}{$30.4 \%(n=79)$} \\
\hline Once a year & \multicolumn{2}{|l|}{$38.5 \%(n=100)$} \\
\hline When there is a problem & \multicolumn{2}{|l|}{$21.2 \%(n=55)$} \\
\hline I do not recommend in routine/ I forget & \multicolumn{2}{|l|}{$10 \%(n=26)$} \\
\hline \multicolumn{3}{|l|}{ When to start brushing teeth? } \\
\hline With the first tooth eruption ** & \multicolumn{2}{|l|}{$40.8 \%(n=106)$} \\
\hline 12. month & \multicolumn{2}{|l|}{$16.5 \%(n=43)$} \\
\hline 18. month & \multicolumn{2}{|l|}{$13.8 \%(n=36)$} \\
\hline 24. month & \multicolumn{2}{|l|}{$28.8 \%(n=75)$} \\
\hline \multicolumn{3}{|l|}{ When to start using toothpaste? } \\
\hline 1 age & \multicolumn{2}{|l|}{$13.8 \%(n=36)$} \\
\hline 2 age & \multicolumn{2}{|l|}{$45 \%(n=117)$} \\
\hline 3 age & \multicolumn{2}{|l|}{$26.2 \%(n=68)$} \\
\hline 4 age & \multicolumn{2}{|l|}{$15 \%(n=39)$} \\
\hline \multicolumn{3}{|c|}{$\begin{array}{l}\text { What is your opinion about the natal/neonatal tooth?You can mark } \\
\text { more than one option. }\end{array}$} \\
\hline Absolutely tooth must be extraction. & \multicolumn{2}{|l|}{$40 \%(n=104)$} \\
\hline $\begin{array}{l}\text { No tooth should be extracted if it is not } \\
\text { mobile and there is no risk of swallowing ** }\end{array}$ & $48.1 \%(n=125)$ & \\
\hline $\begin{array}{l}\text { If the tooth is mobile and there is a risk of } \\
\text { swallowing, the tooth should be extracted } \\
\text { after the } 10 \text { th day of birth. }{ }^{* *}\end{array}$ & $42.3 \%(n=110)$ & $\% 21.5^{* *}$ \\
\hline Absolutely tooth must not be extraction. & $0.4 \%(n=1)$ & \\
\hline
\end{tabular}

*Values are evaluated as percent (\%). $n=$ number of people. ${ }^{* *}$ The correct answers are marked with an ** sign. 
Table 3. Questions and answers about pediatricians' approach to preventive applications and caries protection

\begin{tabular}{|l|c|c|c|}
\hline $\begin{array}{l}\text { Definitely } \\
\text { Yes }\end{array}$ & $\begin{array}{c}\text { No } \\
\text { Idea }\end{array}$ & $\begin{array}{c}\text { Definitely } \\
\text { No }\end{array}$ \\
\hline $\begin{array}{l}\text { Does cariogenic microorganisms(s. } \\
\text { mutans) can pass from mother to baby? }\end{array}$ & $99^{* *}$ & 111 & 50 \\
\hline $\begin{array}{l}\text { Do you think that long-term and } \\
\text { overnight breastfeeding causes caries? }\end{array}$ & $110^{* *}$ & 44 & 106 \\
\hline $\begin{array}{l}\text { Do you think the use of feeding bottles } \\
\text { (milk, baby formula, sugary drinks etc.) } \\
\text { causes caries? }\end{array}$ & $247^{* *}$ & 9 & 4 \\
\hline $\begin{array}{l}\text { Can malocclusion occur in a 3-year- } \\
\text { old child who uses feding bottle or a } \\
\text { pacifier? }\end{array}$ & $240^{* *}$ & 13 & 7 \\
\hline $\begin{array}{l}\text { Would you recommend applying fluorid } \\
\text { gel or fluorine varnish? }\end{array}$ & $121^{* *}$ & 77 & 62 \\
\hline $\begin{array}{l}\text { Would you recommend fissure sealant } \\
\text { applications? }\end{array}$ & $73^{* *}$ & 172 & 15 \\
\hline $\begin{array}{l}\text { Would you recommend space } \\
\text { maintainer / child prosthesis } \\
\text { applications? }\end{array}$ & $247^{* *}$ & 164 & 32 \\
\hline $\begin{array}{l}\text { Should caries on primary teeth be } \\
\text { treated? }\end{array}$ & & 11 \\
\hline $\begin{array}{l}\text { When you detect caries, do you refer it } \\
\text { to the dentist? }\end{array}$ & & & 3 \\
\hline
\end{tabular}

* Values are evaluated as the number of people. ** The correct answers are marked with an ** sign.

Table 4. Questions and answers about the knowledge of tooth eruption and tooth anatomy

\begin{tabular}{|c|c|}
\hline & Value* \\
\hline \multicolumn{2}{|c|}{$\begin{array}{l}\text { How many months should the child be so that we } \\
\text { can diagnose "delayed tooth eruption" in a child? }\end{array}$} \\
\hline 12 month & $21.2 \%(n=55)$ \\
\hline 15 month & $39.2 \%(n=102)$ \\
\hline 18 month** & $34.2 \%(n=89)$ \\
\hline 24 month & $5.3 \%(n=14)$ \\
\hline \multicolumn{2}{|c|}{$\begin{array}{l}\text { When does the permanent } 1 \text {. molar tooth usually erupt } \\
\text { in children? }\end{array}$} \\
\hline 6 age $* *$ & $42.3 \%(n=110)$ \\
\hline 7 age & $31.9 \%(n=83)$ \\
\hline 8 age & $14.6 \%(n=38)$ \\
\hline 9 age & $11.1 \%(n=29)$ \\
\hline \multicolumn{2}{|c|}{ Which is permanent 1. molar tooth? (Figure 1). } \\
\hline $1^{* *}$ & $35 \%(n=91)$ \\
\hline 2 & $16.1 \%(n=42)$ \\
\hline 3 & $48.8 \%(n=127)$ \\
\hline
\end{tabular}

*Values are evaluated as percent (\%). $n=$ number of people. ${ }^{* *}$ The correct answers are marked with an ** sign.
Table 5. Comparison of groups of variables based on total scores

\begin{tabular}{|c|c|c|c|c|}
\hline Variables & Grup & $\operatorname{Avg} \pm s d$ & $\begin{array}{c}\text { Test } \\
\text { Value }\end{array}$ & $\mathrm{p}$ Value \\
\hline \multirow{2}{*}{ Gender } & Female & $9.82 \pm 2.7$ & \multirow{2}{*}{$2.032^{\mathrm{a}}$} & \multirow{2}{*}{$0.043^{*}$} \\
\hline & Male & $9.12 \pm 2.8$ & & \\
\hline \multirow{4}{*}{ Age } & $25-30$ & $8.8 \pm 2.44$ & \multirow{4}{*}{$0.236^{b}$} & \multirow{4}{*}{$<0.001$} \\
\hline & $31-36$ & $8.9 \pm 2.6$ & & \\
\hline & $37-42$ & $10.41 \pm 2.49$ & & \\
\hline & 43 and over & $10.82 \pm 3.33$ & & \\
\hline \multirow{4}{*}{ Experience } & $0-5$ & $2.7 \pm 0.24$ & \multirow{4}{*}{$7.079^{b}$} & \multirow{4}{*}{$<0.001$} \\
\hline & $5-10$ & $2.45 \pm 0.32$ & & \\
\hline & $10-15$ & $2.39 \pm 0.37$ & & \\
\hline & 15 and over & $3.28 \pm 0.63$ & & \\
\hline
\end{tabular}

Avg; average, sd; standard deviation, $a$; The significance test (t-test) value of the difference between the two means, $b$; ANOVA test $F$ Value, ${ }^{*} p<0.05$ There is a statistically significant difference between the groups.

Table 6. Relationship of pediatricians' knowledge of permanent 1. molar teeth with gender

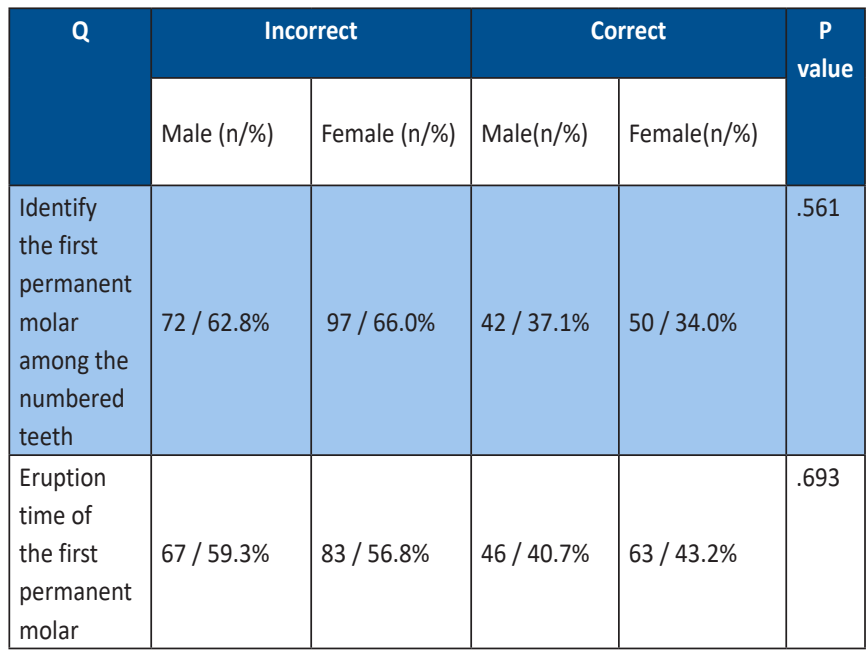

${ }^{*} p>0.05$, There is not a statistically significant difference between the groups.

Table 7. Distribution of PHG treatment responses according to professional experience

\begin{tabular}{|c|c|c|c|c|c|c|}
\hline \multirow{3}{*}{$\begin{array}{l}\text { Experience } \\
\text { (Year) }\end{array}$} & \multicolumn{4}{|c|}{ PHG Treatment } & & \\
\hline & \multicolumn{2}{|c|}{ False } & \multicolumn{2}{|c|}{ True } & \multicolumn{2}{|c|}{ Total } \\
\hline & $n$ & $\%$ & $\mathrm{n}$ & $\%$ & $\mathrm{n}$ & $\%$ \\
\hline $0-5$ & \multicolumn{2}{|c|}{$10682.2 \%$} & \multicolumn{2}{|c|}{$2317.8 \%$} & \multicolumn{2}{|c|}{$129100.0 \%$} \\
\hline $5-10$ & \multicolumn{2}{|c|}{$4777.0 \%$} & \multicolumn{2}{|c|}{$1423.0 \%$} & \multicolumn{2}{|c|}{$61100.0 \%$} \\
\hline $10-15$ & \multicolumn{2}{|c|}{$3173.8 \%$} & \multicolumn{2}{|c|}{$1126.2 \%$} & \multicolumn{2}{|c|}{$42100.0 \%$} \\
\hline$>15$ & \multicolumn{2}{|c|}{$1553.6 \%$} & \multicolumn{2}{|c|}{$1346.4 \%$} & \multicolumn{2}{|c|}{$28100.0 \%$} \\
\hline Total & \multicolumn{2}{|c|}{$19976.5 \%$} & \multicolumn{2}{|c|}{$6123.4 \%$} & \multicolumn{2}{|c|}{$260100.0 \%$} \\
\hline
\end{tabular}

" $p=0.27, p<0.05$ There is a statistically significant difference between the groups. 


\section{DISCUSSION}

This survey was conducted to evaluate pediatricians' attitudes and practices regarding oral health through the data obtained from a random sampling in Turkey. Furthermore, it was aimed to create awareness about oral health in pediatricians and to emphasize the importance of oral health in basic medical education.

Based on the knowledge of 260 pediatricians, the average correct answer score of the 22 questions is less than $50 \%$. A statistically significant difference was found between genders according to the total scores of the participants included in the study ( $p<0.05$, Table 5$)$. In the study of Sezer et al. (2), while the correct answer score of female was $50 \%$ higher than male, there was no relationship between years of experience and correct answer score. In the study of Indira et al. (17), the group with more than 10 years of medical experience had a higher score for correct answers. In the current study, the mean knowledge score of pediatricians with 15 years and more experience were significantly higher than the other groups ( $p<0.05$, Table 5 ).

While $38 \%$ of the participants reported that the bacteria that cause caries can pass from mother to baby, $42.6 \%$ of the pediatricians had no idea about this condition. Cariogenic microorganisms ( $S$. mutans) transmits from mother to baby from mouth to mouth (13). According to the "Caries Assessment Tool-CAT" developed by the American Academy of Pediatric Dentistry (AAPD), the presence of active caries in the mother is a reason for the child to be included in the high-risk group for caries (14). Early acquisition of S. mutans is an important risk factor for early childhood caries (ECC) and future caries experiences (15). The risk of developing caries increases when S. mutans is acquired at an early age, which can be partially prevented by other factors such as good oral hygiene and a non-cariogenic diet (16).

In many studies comparing the cariogenicity of cow's milk with that of breast milk, it was found that breast milk contains a high concentration of lactose with lower mineral and protein content. When breast milk was compared with cow's milk kept for the same period, the decrease in $\mathrm{pH}$ level in mother's milk was higher, which was considered to be effective in the development of smooth surface caries (17). Current literature has demonstrated the risk of ECC is increased in children who are breastfed and/or sleep at the breast for a long time (14). $40.7 \%$ of the participants think that breast milk will not cause caries. Breastfeeding should not be in the form of the baby sucking milk while lying next to the mother at any time and sleeping with milk in her mouth. Instead, breastfeeding should be at regular intervals, with the mother holding her baby in her lap in a sitting position. This form of breastfeeding also reduces the risk of ECC (17).

Bottle-feeding is not the only reason for ECC, it is an important risk factor when combined with poor oral hygiene (14). In their study, Indira et al. reported that $75 \%$ of pediatricians knew that "ECC occur in bottle-fed children" (17). In this survey, $95 \%$ of the pediatricians stated that if the baby drinks 'milk, formula or any beverage containing sweetener' with a bottle, it will cause ECC. It was observed that pediatricians in Turkey are knowledgeable on this subject and achieved the highest rate of correct answers among all questions.

While AAPD previously suggested that the first dental examination should be done around 36 months, in the current treatment guidelines it is now recommended that it should be performed in the 12 th month. With this new view, there has been a consensus on AAPD oral health guidelines which recommend that the first dental examination should be made at the latest in the 12th month or when the first tooth erupts (18). Wagner et al. (19) reported that $63 \%$ of the pediatricians in Germany who participated in the research said the first dental examination should be done after the age of 2. While the study, conducted in Canada by Prakash et al. (20), reported that $55.6 \%$ of the participants believed that the first dental examination should be done after 2-3 years of age. In this study, $27 \%$ answered with the eruption of the first tooth, $26.6 \%$ after the age of 1 , and $27.3 \%$ after the age of 2. According to the studies in the literature, although the pediatricians in Turkey are more knowledgeable, still the rate of correct answers in this question is not satisfactory

Acquiring the habit of oral hygiene starts at an early age. AAPD, EAPD, and IAPD have reported that as soon as the first tooth erupts, parents should start brushing the baby's teeth with soft toothbrushes or finger brushes suitable for the age of the baby (21). In this study, the rate of pediatricians who recommended brushing with the eruption of the first tooth was $40.8 \%$, while Murthy and Mohandas (22) reported this rate as $33.3 \%$ in their study.

In this study, $45 \%$ of pediatricians indicated that the first toothpaste should be used at the age of two. To prevent ECC, it is recommended in EAPD's 2019 guideline to use toothpaste as small as a grain of rice for children with ages between six months to two years and the toothpaste use of a size of a pea is recommended for children after two years of age (23).

Fluoride applications are extremely important in preventing caries development. While $46.5 \%$ of pediatricians recommend applying fluoride gel or fluoride varnish, $29.6 \%$ of them abstained by saying that "No idea", and $23.8 \%$ did not recommend fluoride application thinking that they were harmful. It was reported in the studies conducted that blood, urinary values, and tissue accumulation measurements after topical fluoride application was not at a harmful level (24). It is important to pay attention to the concentrations of the agents used, the use of suction, the preference of fluoride varnish in younger age groups, and the frequency of topical application and the daily fluoride intake by the child should be evaluated (23). Many studies on caries conducted to date have shown that the occlusal surfaces are susceptible to caries due to pits and fissures arising from their anatomical structures. While Murthy and Mohandas (22) reported in their study that $84 \%$ of the pediatricians stated that fluoride and fissure sealants would prevent the development of caries, $66.1 \%$ of the pediatricians participating in this study had no idea about 
fissure sealant application. And also, a study conducted in Turkey by Akyildiz et al., had found a similar rate, which was $66 \%(25)$. The serious lack of knowledge of pediatricians in Turkey about preventive practices may be due to the fact that they do not take part in medical education. Moreover, the absence of a follow-up system in which dentists and medical physicians will be in constant communication may have caused this lack of information.

Appliances made to prevent the closure of the gap created by the early lost tooth by neighboring teeth are called "space maintainer". The use of space maintainers is essential to prevent tooth crowding and orthodontic anomalies that may arise (26). It was seen that $67.3 \%$ of pediatricians did not know about the space maintainer/child prosthesis applications.

The number of pediatricians who advocated that caries in primary teeth should be treated $(67.3 \%)$, and the number of physicians who directed their patients to dentists when they detected caries (95\%) was quite high in this study. Dental caries which start in the first years of life increase the risk of caries development in the future. Deep caries can cause the development of pain, abscess and extraoral swelling. Most importantly, infected primary teeth can create defects on the successor permanent teeth, such as enamel opacities, hypoplasias and developmental disorders (27).

After consulting with pediatricians, a question was added about the natal/neonatal tooth, which pediatricians stated that they frequently encountered during neonatal examinations. $40 \%$ of physicians think that these teeth should definitely be extracted. According to the literature, it is reported that approximately $90 \%$ of the natal/neonatal teeth are primary teeth, and only $10 \%$ of them are supernumerary teeth (extra teeth) (28). For this reason, if the natal tooth does not prevent the child from sucking the mother and is asymptomatic, its extraction is not necessary and it is kept under control in the mouth (28). Extraction is indicated if the tooth is extremely mobile, holds weakly in the mouth, and there is a risk of aspiration (28).

Thirty-nine percent (39.2\%) of the physicians answered the delayed tooth eruption as 15 months. The eruption of primary teeth can be delayed until the 12th and even up to 14th months as a genetic feature. Children with no tooth eruption until the 14th month should be investigated in terms of systemic and nutritional disorders such as hypothyroidism, cleidocranial dysostosis, Down syndrome, hypopituitarism, progeria, Albright's Hereditary Osteodystrophy, incontinentia pigmenti, and rickets. Local causes such as small skull base, hyperdontia, ankylosis of primary teeth may also be the cause of delayed tooth eruption. Numerical anomalies of teeth such as anodontia and hypodontia can also be observed in some children (29). If no genetic or systemic problem in the child is detected after analysis and if the tooth still does not erupt after 15 months, the control should be conducted by dentists via $\mathrm{x}$-ray.

For the patient in Figure 2, 76.5\% of pediatricians stated that there would be crowding and $85.3 \%$ thought that orthodontic treatment would be required. The first physicians whom the patients should refer to for this condition are the dentists. The reason for the addition of these questions was that pediatricians frequently consulted with pediatric dentists on this issue and the number of patients referred by pediatricians to the dentists was therefore high. The eruption of permanent lower incisors from the lingual of the primary incisors is one of the leading eruption problems observed in this region. This condition is observed in one in ten children. In most cases, with the development of the root of the permanent tooth, the effect of the tongue, and the growth and development of the alveolar crest, the lower permanent incisor teeth are automatically positioned normally on the dental arch over time (30).

The perioral and oral cavity photograph of a male patient with primary herpetic gingivostomatitis (PHG) was added to the questionnaire after obtaining consent from the parents. Pediatricians were asked two different questions as to what their diagnosis and treatment would be for this patient. While $48.8 \%$ of the physicians made the diagnosis correctly, $64.5 \%$ stated that they would prescribe antibiotics and mouth wash for the patient with primary herpetic gingivostomatitis, which is a viral disease, and refer him/her to the dentist. Besides, pediatricians with 15 years of experience and above gave a significantly higher number of correct answers compared to those with less experience ( $p<0.05$, Table 7$)$. In the treatment of PHG, it is aimed to prevent the further spread of the infection by the healing of the lesions with palliative interventions, adequate fluid supply, and nutrition. Topical anesthetics and coating agents provide pain relief and aid nutrition. Early diagnosis is required for specific treatment with antiviral (acyclovir) (31).

\section{CONCLUSION}

The fact that a small portion of the pediatricians correctly answered information-based questions shows that physicians need oral and dental health training. Lack of information and education seems to limit the role of pediatricians in children's oral and dental health. These results indicate that post-specialist training and courses for pediatricians covering oral and dental health may be beneficial in Turkey. Adding it to the 'medicine core education program' or to the relevant specialist trainings will make future generations more conscious about oral and dental health. Furthermore, the inclusion of dentistry-related content in scientific journals and books for pediatricians can increase awareness on the subject. Cooperation between pediatric dentists and pediatricians is very important; it should be ensured that the communication between them is stronger.

\section{Acknowledgements}

We would like to enounce our sincere thanks to Dr Ridvan Selen who provided a different perspective to our work and did not spare his efforts. 


\section{REFERENCES}

[1] [1] U.S. Department of Health and Human Services Oral Health Coordinating Committee. US department of health and human services oral health strategic framework. Public Health Rep 2016;131(2):242-257.

[2] [2] Sezer RG, Paketci C, Bozaykut A. Paediatricians' awareness of children's oral health: Knowledge, training, attitudes and practices among Turkish paediatricians. Paediatr Child Health 2013;18(4):e15-e9.

[3] [3] Dye BA, Arevalo O, Vargas CM. Trends in paediatric dental caries by poverty status in the United States, 1988-1994 and 1999-2004. Int J Paediatr Dent 2010;20(2):132-143.

[4] [4] Adams PF, Hardy AM. Current estimates from the National Health Interview Survey, 1988;25-71.

[5] [5] Namal N, Vehit H, Can G. Risk factors for dental caries in Turkish preschool children. J Indian Soc Pedod Prev Dent 2005;23(3):115-118.

[6] [6] Köksal E, Tekçiçek M, Yalçin SS, Tugrul B, Yalçin S, Pekcan G. Association between anthropometric measurements and dental caries in Turkish school children. Cent Eur J Public Health 2011;19(3):147-151.

[7] [7] Elamin A, Garemo M, Gardner A. Dental caries and their association with socioeconomic characteristics, oral hygiene practices and eating habits among preschool children in Abu Dhabi, United Arab Emirates the NOPLAS project. BMC oral health 018;18(1):1-9.

[8] [8] Zerfowski M, Koch MJ, Niekusch U, Staehle HJ. Caries prevalence and treatment needs of 7-to 10-year-old schoolchildren in southwestern Germany. Community Dent Oral Epidemiol 1997;25(5):348-351.

[9] [9] Calonge N. Prevention of dental caries in preschool children: recommendations and rationale. Am J Prev Med 2004;26(4):326-329.

[10] [10] Pastor IMO, Siquara da Rocha MCB. Integration of medical and dental pediatrics: an expanded view of health promotion. Rev Ciênc Méd Biol 2003;2(1):62-71.

[11] [11] Schafer TE, Adair SM. Prevention of dental disease: the role of the pediatrician. Pediatr Clin North Am 2000;47(5):10211042.

[12] [12] Faul F, Erdfelder E, Buchner A, Lang AG. Statistical power analyses using G* Power 3.1: Tests for correlation and regression analyses. Behav Res Methods, 2009, 41.4: 11491160.

[13] [13] Berkowitz R, Jones P. Mouth-to-mouth transmission of the bacterium Streptococcus mutans between mother and child. Arch Oral Biol 1985;30(4):377-379.

[14] [14] Casamassimo PS, Warren JJ. Examination, diagnosis, and treatment planning of the infant and toddler. In Pinkham JR, Casamassimo PS, McTigue DJ, Fields HW. Nowak AJ, eds. Pediatric Dentistry: infancy through adolescence. 4th ed. St Louis (MO): Elsevier Saunders; 2005. p. 206.
[15] [15] Berkowitz RJ. Mutans streptococci: acquisition and transmission. Pediatr Dent. 2006; 28(2): 106-109.

[16] [16] Harris R, Nicoll AD, Adair PM, Pine CM. Risk factors for dental caries in young children: a systematic review of the literature. Community Dent Health 2004; 21(1 suppl): 71-85.

[17] [17] Indira MD, Kanika Singh Dhull, Nandlal B. Knowledge, attitude and practice toward infant oral healthcare among the pediatricians of mysore: a questionnaire survey. Int J Clin Pediatr Dent 2015; 8: 211-214.

[18] [18] Nowak AJ. Oral health policies and clinical guidelines. Pediat Dent. 2007;29(2):138-139.

[19] [19] Wagner $Y$, Heinrich-Weltzien R. Pediatricians' oral health recommendations for 0-to 3-year-old children: results of a survey in Thuringia, Germany. BMC Oral Health 2014; 14: 4449.

[20] [20] Prakash P, Lawrence HP, Harvey BJ, Mclsaac WJ, Limeback $\mathrm{H}$, Leake JL. Early childhood caries and infant oral health: paediatricians' and family physicians' knowledge, practices and training. Paediatr Child Health 2006; 11: 151-157.

[21] [21] Berkowitz RJ. Causes, treatment and prevention of early childhood caries: a microbiologic perspective. J Can Dent Assoc 2003 May 1;69(5):304-307.

[22] [22] Murthy GA, Mohandas U. The knowledge, attitude and practice in prevention of dental caries amongst pediatricians in Bangalore: A cross-sectional study. J Indian Soc Pedod Prev Dent 2010; 28: 100-103.

[23] [23] Toumba KJ, Twetman S, Splieth C, Parnell C, Loveren $C$, Lygidakis NA. Guidelines on the use of fuoride for caries prevention in children: an updated EAPD policy document. Eur Arch Paediatr Dent 2019; 20: 507-516.

[24] [24] Heath K, Singh V, Logan R, McIntyre J. Analysis of fluoride levels retained intra orally oringested following routine clinical applications of topical fluoride products. Aust Dent J 2001; 46: 24-31.

[25] [25] Akyıldız MB, Doğusal G, Sönmez I. Knowledge of Pediatricians in Aydın and İzmir Regarding Oral and Dental Health. J Pediatr Res 2015; 2(1): 21-25.

[26] [26] Watt E, Ahmad A, Adamji R, Katsimbali A, Ashley P, Noar $J$. Space maintainers in the primary and mixed dentition-a clinical guide. Br Dent J. 2018; 225(4):293-298.

[27] [27] Broadbent JM, Thomson WM, Williams SM. Does caries in primary teeth predict enamel defects in permanent teeth? A longitudinal study. J Dent Res 2005; 84(3): 260-264.

[28] [28] Kates GA, Needleman HL, Holmes LB. Natal and neonatal teeth: a clinical study. J Am Dent Assoc 1984;109(3):441-443.

[29] [29] Saner G, Durmaz Ö. Ağız Boşluğu. Ed: Neyzi O, Ertuğrul TY. In Pediyatri,1.Cilt. 4. Baskı. İstanbul; Nobel Yayınları; 2010: 917-923.

[30] [30] Gökçek M, Bodrumlu EH, Özkalaycı N. Diş sürmesi. Yeditepe J Dent 2016; 12(3): 35-44.

[31] [31] Yildirim D, Haştar E, Yilmaz HH, Aydin Ü. Primary herpetic gingivostomatitis: Three case reports. ADO J Clin Sci 2011; 5(2): 903-908 